\title{
Detection of Interleukin 6-Producing Cells among Various Organs in Normal Mice with an Improved Enzyme-Linked Immunospot (ELISPOT) Assay
}

\author{
YOSHIHIRO OKAMOTO, HIROKO MURAKAMI, AND MIKIO NISHIDA \\ Department of Clinical Pharmacy, Faculty of Pharmacy, Meijo University, Nagoya 468, Japan
}

\begin{abstract}
The enzyme-linked immunospot (ELISPOT) assay is an efficient technique for the enumeration of single cells secreting antibodies or cytokines. To assess mice interleukin 6 (IL-6)secreting cells at a single cell level, a highly sensitive ELISPOT assay with 5-bromo-4-chloro-3indolylphosphate $p$-toluidine salt and nitroblue tetrazolium chloride (BCIP/NBT) as a gel-substrate has been developed. The IL-6 specific ELISPOT assay thus developed with an ordinary plastic ELISA plate is as efficient as the previous IL-6 specific ELISPOT assay system which uses a nitrocellulose coated plate, and is much more economic and convenient. We demonstrated with this newly devised ELISPOT assay that the ratio of IL-6 producing cells in the resident peritoneal exuded cells was highest in normal $\mathrm{BALB} / \mathrm{c}$ mice, and a few IL-6 secreting cells were detected in all organs we tested, namely the spleen, bone marrow, Peyer's patch, axillary lymph node and thymus.
\end{abstract}

Key words: Interleukin 6, Enzyme-linked immunospot assay, 5-Bromo-4-chloro-3-indolylphosphate $p$ toluidine salt and nitroblue tetrazolium chloride, Cytokine secretion, BALB/c mouse

(Endocrine Journal 44: 349-355, 1997)

INTERLEUKIN 6 (IL-6) is an important multifunctional cytokine which is involved in the regulation of a variety of cellular responses, such as the induction of acute-phase protein synthesis, lymphocyte activation and hematopoiesis [1-4]. Recent studies with IL-6 deficient mice generated by gene targeting have demonstrated that IL- 6 plays extremely important roles in acute-phase responses $[5,6]$.

IL-6, having a M.W. of $26 \mathrm{kDa}$ and originally cloned from a murine $\mathrm{T}$ cell line, is present in supernatants from a variety of cultured cell lines. Multiple cell types can secrete IL-6 when stimulated in vitro $[1,2]$. IL- 6 has been detected in sera of

Received: July 24, 1996

Accepted: February 6, 1997

Correspondence to: Dr. Yoshihiro OKAMOTO, Department of Clinical Pharmacy, Faculty of Pharmacy, Meijo University, 150 Yagotoyama, Tempaku-ku, Nagoya 468, Japan normal individuals, and abnormalities in IL-6 levels are associated with diseases of the immune system such as systemic lupus erythematosus (SLE) [7], psoriasis [8], rheumatoid arthritis (RA) [9] and acquired immunodeficiency syndrome (AIDS) [10].

It is obvious that further understanding of the roles of IL- 6 in the immune responses depends on the quantitative measurement of the cytokine levels. Various approaches have been carried out for measuring IL-6 production. Direct assays of the cytokine in a body fluid or the supernatant of cultured cells took place by means of ELISA [11] or a bioassay using the IL-6-dependent cell line [12]. Measurement of expressed mRNA has been extensively applied to many studies on the production of IL- 6 by various cells and tissues [13, 14], but micro-levels of dynamic immune responses produced by cytokines are hardly detected by the gross measurements mentioned above. Since the detection of newly synthesized cytokines by an 
individual secreting cell in various locations may contribute to an understanding of the roles of the cytokine in complicated immune responses, we need to develop finer techniques to measure the micro-dynamic distribution of cytokines.

In the present study, we have devised a highly specific ELISPOT assay for IL-6 with a combination of two kinds of dyes as a staining technique for detection, and applied the assay system to detect IL-6 secreting cells at a single cell level in various organs of female BALB/c mice. This report shows that under physiological conditions peritoneal exuded cells were the most active IL- 6 secreting cells in the spleen, bone marrow, thymus, axially lymph node and Peyer's patch cells.

\section{Materials and Methods}

\section{Reagents}

Pairs of unlabeled (coating antibody, clone MP520F3) and biotin-labeled (detection antibody, clone MP5-32c11) monoclonal antibodies (mAbs) for mouse IL-6 were purchased from Pharmingen Co., Ltd. (San Diego, CA, USA). Biotin-labeled mAbs for mouse IL-4 (clone BVD6-24G2) and mouse CD90 (Thy-1.2, clone 30-H12), which were used as an unrelated antibody, were also purchased from Pharmingen Co., Ltd. Avidin-conjugated alkaline phosphatase was purchased from GIBCO BRL Co., Ltd. (Grand Island, NY, USA). Concanavalin A (Con A) was a product from Sigma Chemical Co., Ltd. (St. Louis, MO, USA).

\section{Animals}

Specific-pathogen-free BALB/c female mice were obtained from Japan SLC, Inc. (Shizuoka, Japan) and used throughout the study. The mice were maintained in laminar flow cabinets and provided sterile food and water ad libitum. All animals were 8-9 weeks of age when used.

\section{Cell preparation}

To obtain resident peritoneal exuded cells, mice were killed by cervical dislocation under anesthesia with ether, and the cells were harvested by peritoneal lavage with $8 \mathrm{ml}$ of RPMI 1640 medium
(Nissui Co., Ltd., Tokyo, Japan). After washing three times with the same medium, the resident peritoneal exuded cells were resuspended in the medium supplemented with $10 \%$ heat-inactivated fetal bovine serum (FBS, GIBCO BRL Co., Ltd., Grand Island, NY, USA). Spleen cells were prepared as described previously [15]. The spleen was aseptically removed and mechanically disrupted. A dispersed cell suspension was filtered through a mesh and the red blood cells were lysed with Tris-buffered $0.83 \% \mathrm{NH}_{4} \mathrm{Cl}$ solution. After washing three times with the medium, spleen cells were resuspended in the medium supplemented with 10\% FBS. The Peyer's patch, thymus, and axillary lymph node were prepared by essentially the same method as that for spleen cells. Bone marrow cells were prepared, as described previously [16], from femurs and tibias of mice.

\section{ELISPOT assay specific to IL-6}

A plastic 96-well ELISA plate (MS-8596F/H plate, SUMITOMO BAKELITE Co., Ltd., Tokyo, Japan) was coated with $2 \mu \mathrm{g} / \mathrm{ml}$ (100 $\mu \mathrm{l} /$ well) of $\mathrm{mAb}$ anti-IL-6 (clone MP5-20F3) in 0.1 M bicarbonate buffer ( $\mathrm{pH} 8.2)$. The plate was then blocked with $5 \%$ bovine serum albumin (BSA, Sigma Chemical Co., St. Louis, MO, USA) in phosphate buffer saline (PBS) for $2 \mathrm{~h}$ at room temperature. Con Astimulated or non-stimulated cells resuspended in RPMI 1640 with $10 \%$ FBS were put into individual wells $\left(1 \times 10^{3}\right.$ to $1 \times 10^{5} \mathrm{cells} / 100 \mu \mathrm{l} /$ well $)$ and incubated for $18 \mathrm{~h}$ at $37{ }^{\circ} \mathrm{C}$ in a humidified atmosphere of $5 \% \mathrm{CO}_{2}$ in air. The plate was thoroughly washed with PBS containing $0.05 \%$ Tween 20 (PBS-Tween) and then incubated overnight at $4{ }^{\circ} \mathrm{C}$ with $100 \mu$ l of biotinylated mAb anti-IL-6 $(1 \mu \mathrm{g} / \mathrm{ml})$ (clone MP5-32c11) in PBSTween containing $1 \%$ BSA. The plate was washed with PBS-Tween and further incubated with avidinconjugated alkaline phosphatase (diluted 1:2000, $100 \mu \mathrm{l} /$ well). Stained spots of IL- 6 secreted by individual cells were developed with the 5-bromo4-chloro-3-indolylphosphate $p$-toluidine salt (BCIP) and nitroblue tetrazolium chloride (NBT) mix substrate (BCIP/NBT stable mixture, GIBCO BRL., Grand Island, NY, USA) which was dissolved at $40{ }^{\circ} \mathrm{C}$ in $0.6 \%(\mathrm{w} / \mathrm{v})$ agarose (Nakarai tesq. Co., Ltd., Kyoto, Japan). This gel substrate yields a purple-colored precipitate in the presence of the 
phosphatase. The purple-colored spots were developed during a 4 -h incubation period at room temperature and could be counted with an inverted microscope. The cell specimen was sequentially diluted to detect appropriate numbers of the spots in a well, and the conditions to produce 10-100 spots/well were used to count the total number of IL-6 secreting cells per sample. Stained artifacts were easily distinguished from the spots of secreted IL-6 due to the size and stainability of contaminated objects.

\section{Results}

Improvement in sensitivity of the ELISPOT assay with a gel substrate

To identify individual IL-6 producing cells, the optimal conditions for IL-6 ELISPOT assay were examined. Spleen cells prepared from BALB/c mice, which secrete IL- 6 constitutively $[14,17]$, were incubated in $\mathrm{mAb}$ anti-IL-6 precoated wells. Table 1 showed that when BCIP was singly used as a gel-substrate [18-20], the resultant numbers of spots that represented secretion of IL-6 were not parallel with those of cells added to a well, but the combination of BCIP and NBT improved the sensitivity enough to detect the site of IL-6 secreting cells. The number of purple spots increased as more cells were added to a well. A typical profile of the ELISPOT assay with BCIP/NBT is shown in
Fig. 1.

To optimize the concentration of the coating $\mathrm{mAb}$, spleen cells were added to the wells coated with various concentrations $(0-5 \mu \mathrm{g} / \mathrm{ml})$ of $\mathrm{mAb}$ anti-IL-6. Figure 2 shows that the concentrations with over $1 \mu \mathrm{g} / \mathrm{ml}$ of the $\mathrm{mAb}$ were enough to detect the spot of secreted IL-6.

\section{Specificity of the ELISPOT assay}

Whether or not the newly improved ELISPOT assay is specific for an IL-6 secreting cell, was tested. First, the specificity of both the coating $\mathrm{mAb}$ (MP5-20F3) and the detection mAb (MP532c11) to mouse IL-6 was examined by ELISA with recombinant mouse IL-6 as a positive control and other types of cytokine (mouse IL-1, IL-2 and IL-4) as a negative control. The ELISA assay in the combination of these antibodies was only positive with mouse IL-6 in a dose-dependent manner, and was negative when tested with mouse IL-1, IL-2 and IL-4 (data not shown). Second, anti mouse IL$6 \mathrm{mAb}$ was replaced with anti mouse IL-4 mAb (clone BVD6-24G2) or anti mouse CD90 mAb (clone 30-H12), as an unrelated antibody. No IL-6 specific spots were formed (data not shown). Third, spots were not formed in the well without the coating $\mathrm{mAb}$ (Fig. 2). Fourth, as stated before, when the amount of inoculating cells in a well was increased, the spot formation was also increased in parallel fashion (Table 1). And fifth, after the spleen cells were pretreated with $0.5 \mathrm{mM}$ and 1

Table 1. Number of spot forming cells (SFC) depends on the number of cells added to a well

\begin{tabular}{|c|c|c|c|c|c|}
\hline Gel substrate & Cell number/well & $10^{4}$ & $10^{3}$ & $10^{2}$ & 0 \\
\hline \multirow[t]{2}{*}{$\mathrm{BCIP} / \mathrm{NBT}$} & $\begin{array}{l}\text { Number of SFC } \\
\text { (SD) }\end{array}$ & $\begin{array}{l}138.3 \\
(62.8)\end{array}$ & $\begin{array}{l}17.2 \\
(3.8)\end{array}$ & $\begin{array}{c}3.0 \\
(1.9)\end{array}$ & $\begin{array}{c}0.5 \\
(0.5)\end{array}$ \\
\hline & $\begin{array}{l}\text { SFC ratio (\%) } \\
\text { (SD) }\end{array}$ & $\begin{array}{c}1.38 \\
(0.63)\end{array}$ & $\begin{array}{c}1.72 \\
(0.38)\end{array}$ & $\begin{array}{c}3.00 \\
(1.90)\end{array}$ & $(-)$ \\
\hline \multirow[t]{2}{*}{$\mathrm{BCIP}$} & $\begin{array}{c}\text { Number of SFC } \\
\text { (SD) }\end{array}$ & $\begin{array}{c}0.6 \\
(1.2)\end{array}$ & $\begin{array}{c}0.0 \\
(0.0)\end{array}$ & $\begin{array}{c}0.3 \\
(0.6)\end{array}$ & $\begin{array}{c}0.3 \\
(0.6)\end{array}$ \\
\hline & $\begin{array}{l}\text { SFC ratio (\%) } \\
\text { (SD) }\end{array}$ & $\begin{array}{c}0.01 \\
(0.00)\end{array}$ & $\begin{array}{c}0.00 \\
(0.00)\end{array}$ & $\begin{array}{c}0.30 \\
(0.60)\end{array}$ & $\begin{array}{l}- \\
(-)\end{array}$ \\
\hline
\end{tabular}

Various numbers of spleen cells were added to the well coated with 2 $\mu \mathrm{g} / \mathrm{ml}$ anti IL-6, and spots were developed by using BCIP/NBT or $\mathrm{BCIP}$ alone as described in Materials and Methods. Values are expressed as the mean SFC numbers ( \pm SD) in 6 assay wells. 


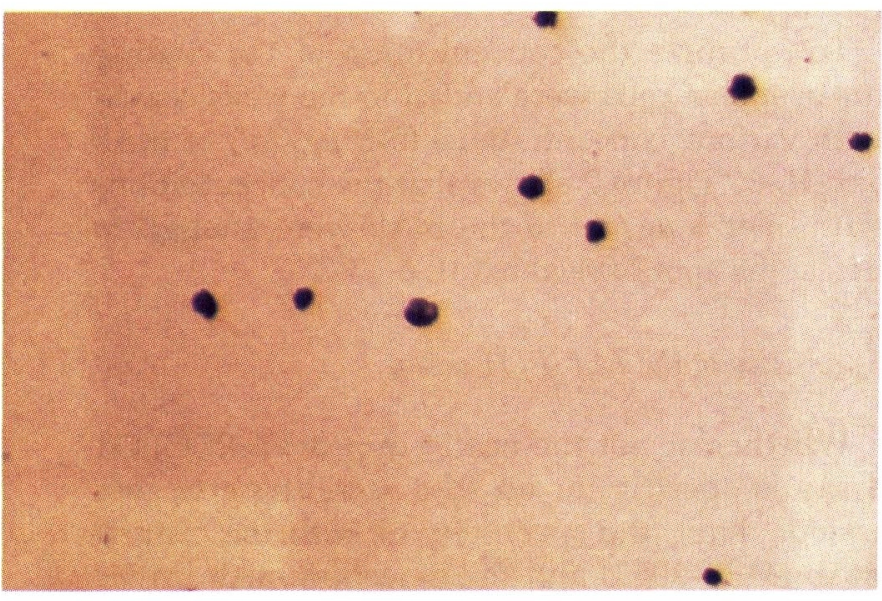

Fig. 1. Typical appearance of IL-6-specific spot produced by spleen cells in normal BALB/c mice. Spleen cells prepared from normal BALB/c mice were added to anti-IL-6 antibody (MP5-20F3) coated wells. After 18-h incubation at $37^{\circ} \mathrm{C}$ in a humidified atmosphere of $5 \% \mathrm{CO}_{2}$ in air, spots were developed by sequential incubation with biotinylated anti-IL-6 antibody (MP5-32c11), avidin-conjugated alkaline phosphatase and BCIP/NBT gel substrate $(\times 100)$.

$\mathrm{mM}$ cycloheximide for $2 \mathrm{~h}$, the treated cells were activated with $1 \mu \mathrm{g} / \mathrm{ml}$ Con $A$ for $18 \mathrm{~h}$. The pretreatment with $0.5 \mathrm{mM}$ and $1 \mathrm{mM}$ cycloheximide reduced the number of IL-6 secreting cells by 60 percent and 73 percent of the control, respectively. Neither concentration of cycloheximide affected cell viability which was assessed by trypan blue dye exclusion test.

\section{Detection of a major site of IL-6 production in normal $B A L B / c$ mice}

Single cell suspensions were prepared from the spleen, bone marrow, Peyer's patch, axillary lymph node, thymus and resident peritoneal exuded cells of normal BALB/c mice. The IL-6 specific ELISPOT assay system was tested on these isolated cells. The results in Fig. 3 showed the population of detected IL-6 secreting cells in each tested cell suspension. The estimated frequency of IL-6 secreting cells under physiological conditions was $24.7 \pm 8.5$ cells $/ 10^{3}$ resident peritoneal exuded cells (1.6-3.3 percent), $17.7 \pm 3.2$ cells $/ 10^{3}$ axillary lymph node cells (1.5-2.1 percent), $14.3 \pm 2.0$ cells $/ 10^{3}$ spleen cells (1.2-1.7 percent), $10.7 \pm 3.9$ cells $/ 10^{3}$ bone marrow cells ( $0.7-1.5$ percent), $7.7 \pm 1.5$ cells /

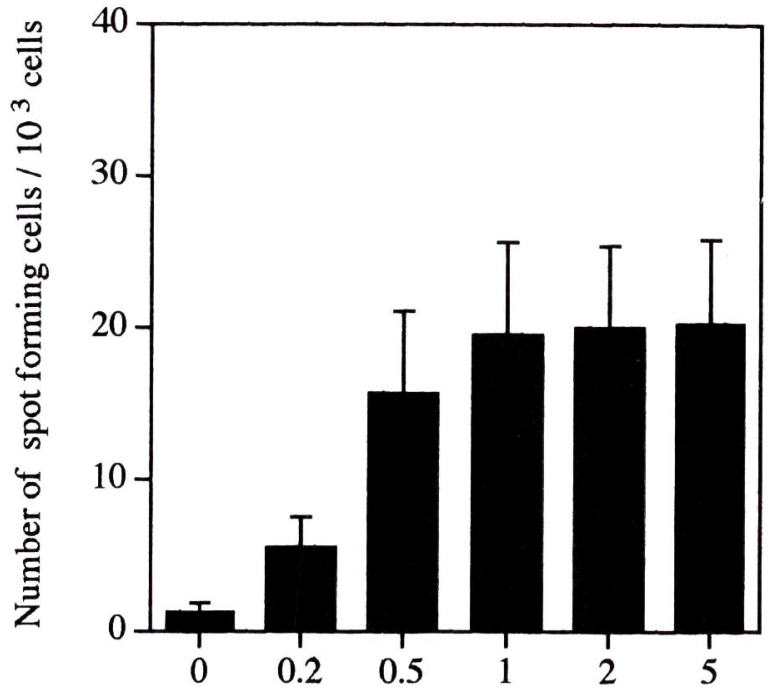

Concentration of coating antibody $(\mu \mathrm{g} / \mathrm{ml})$

Fig. 2. Optimization of amount of coating antibody. Spleen cells were added to the wells coated with several concentrations $(0-5 \mu \mathrm{g} / \mathrm{ml})$ of antibody, and subsequently spots were developed as described in Materials and Methods. Each bar represents the mean values $\pm S D$ in 6 experiments.

$10^{3}$ Peyer's patch cells (0.6-0.9 percent), and $6.7 \pm$ 0.6 cells $/ 10^{3}$ thymus cells $(0.5-0.8$ percent). The frequency of IL-6 secreting cells in resident peritoneal exuded cells was significantly higher than that in bone marrow or spleen cells, which were previously reported as the major source of IL-6 secreting cells [17].

\section{Discussion}

The purpose of the present study was to differentiate IL-6 secreting cells from non-cytokine secreting cells in an efficient manner. To this end, it was necessary to develop a more highly sensitive ELISPOT assay system with a gel substrate than that previously used.

Czerkinsky et al. were the first to describe a new assay procedure for the detection and enumeration of antibody-producing cells at the single cell level [18]. This technique is a modification of an ELISA assay, and is commonly known as an enzymelinked immunospot (ELISPOT) assay.

Only BCIP has been used as a substrate in a gel 


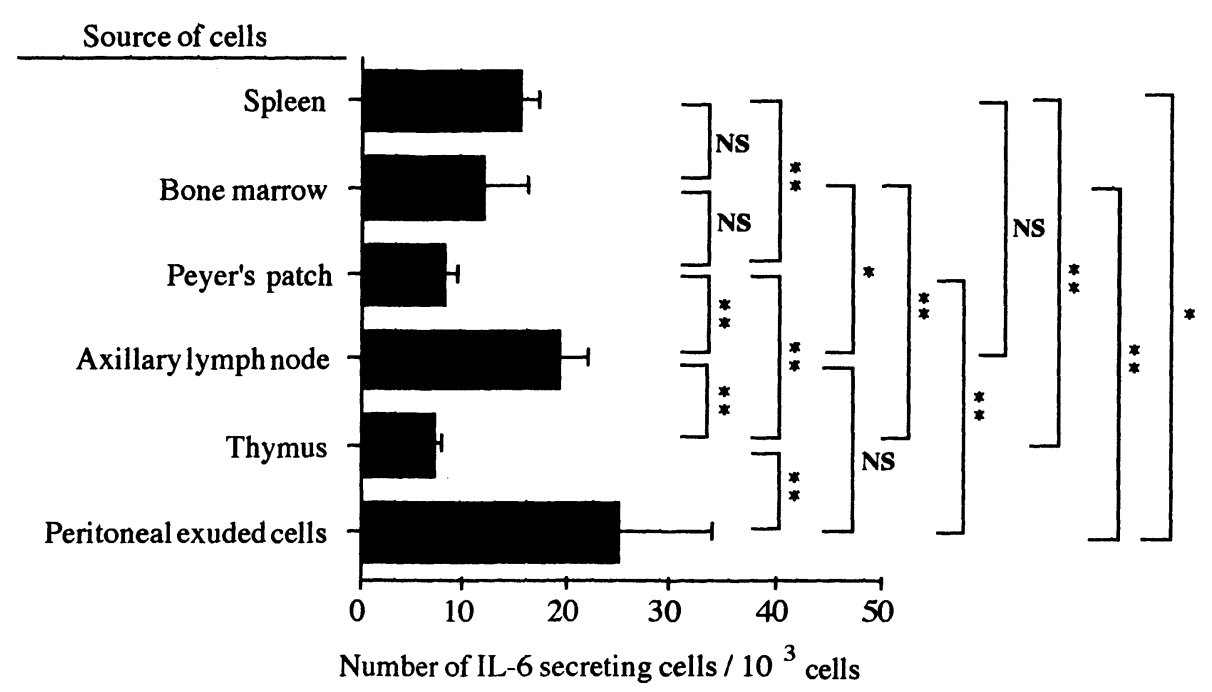

Fig. 3. Detection of IL-6 secreting cells in normal BALB/c mice. The number of cells secreting IL-6 per $10^{3}$ spleen, bone marrow, Peyer's patch, axillary lymph node, thymus, and peritoneal exuded cells was measured in normal BALB/c mice by ELISPOT assay. The results represent the mean values \pm SD in 6 assay wells from two identical experiments, using 3 wells each time. Each experiment was carried out with cells obtained from 6 mice to obtain sufficient cells. Significant differences were determined by Student's $t$-test. ${ }^{* *} P<0.01,{ }^{*} P<0.05$. NS, no significance.

for the ELISPOT assay system to detect antibody or cytokine producing cells [18-20]. At first we also tested BCIP alone as a gel-substrate to detect the spot of secreted IL-6, but the system could not stain individual cells of interest, because the chromogen generated from BCIP alone was easily diffused in the agarose gel. The cells secreting a little amount of IL- 6 were therefore not detected. It was our device that to add NBT, which yielded a water insoluble product, to the BCIP gel substrate, resulted in an increase in the stainability of the spot. The speculated mechanism in the color reaction of $B C I P / N B T$ mix substrate is initiated by the cleavage of the $\mathrm{P}-\mathrm{O}$ bond in BCIP by alkaline phosphatase. The resultant indoyl moieties tend to form a dimeric compound which yields a purple color. This reaction emits hydride ion, which reduces NBT to yield an insoluble precipitate. Thus the overall reaction may produce a solid purple precipitate.

In the present study we used an ordinary plastic 96-well ELISA plate, instead of the nitrocellulose coated plate previously reported by other investigators [17, 21, 22]. We tested both types of plates, and found that the efficacy of the two plates was quite similar in the assay (data not shown), but the ordinary plastic plate was 8 times more economical and technically more convenient with a laboratory ELISA apparatus.

The specificity of the modified ELISPOT assay was carefully characterized by various lines of evidence that are described in the text: the stained spot formation required the right combination of antibodies and the antigen (mouse IL-6). And, the absence of coating-antibodies in the assay system resulted in no spot formation. Furthermore, the treatment with cycloheximide reduced the IL-6 specific spot formation by spleen cells due to the inhibition of the de novo synthesis of protein.

Cells obtained from various organs in normal female mice under physiological conditions were applied to determine cell populations which produce IL-6 (Fig. 3). We revealed that resident peritoneal exuded cells were the major source of IL-6 secretion in all organs we tested. The frequency of IL-6 secreting cells in resident peritoneal exuded cells or in axillary lymph node cells was significantly higher than that in bone marrow cells (Fig. 3), which were reported as the main source of IL-6 secretion in normal BALB/c 
mice by Shirai et al. [17]. We also newly demonstrated that there were IL- 6 secreting cells in Peyer's patch and the thymus in normal BALB/ $c$ mice. These lines of evidence are a new addition to the profile of distribution of IL-6 secreting cells, such as macrophages in peritoneal exuded fluids [23] and mesentric lymph node cells [17] in BALB/ c mice under physiological conditions.

In summary, we have developed a reliable method to detect cells producing IL-6 at the single cell level. This procedure provides a powerful tool for quantitatively investigating complicated immune responses.

\section{References}

1. Ikebuchi K, Wong GG, Clark SC, Ihle JN, Hirai Y, Ogawa M (1987) IL-6 enhancement of IL-3 dependent proliferation of multipotential hemopoietic progenitors. Proc Natl Acad Sci USA 84: 9035-9039.

2. Hirano $T$, Yasukawa $H$, Harada $T$, Taga $T$, Watanabe Y, Matsuda T, Kashiwamura S, Nakajima K, Koyama K, Iwamatsu A, Tsunasawa S, Sakiyama F, Matsui H, Takahara Y, Taniguchi T, Kishimoto T (1986) Complementary DNA for novel human interleukin (BSF-2) that induces B lymphocytes to produce Ig. Nature 324: 73-76.

3. Garman RK, Jacobs K, Clark SC, Raulet D (1987) B cell stimulatory factor $2 /$ interferon $\beta 2$ functions as a second signal for IL-2 production by mature T cells. Proc Natl Acad Sci USA 84: 7629-7635.

4. Castell JV, Gomez-Lechan MJ, David M, Andus T, Geiger T, Trullenque R, Fabra R, Heinrich PA (1989) Interleukin-6 is the major regulator of acute-phase protein synthesis in adult human hepatocytes. FEBS lett 242: 237-239.

5. Kopf M, Baumann H, Freer G, Freudenberg $M$, Lamers M, Kishimoto T, Zinkernagel R, Bluethmann $H$, Kohler G (1994) Impaired immune and acutephase responses in interleukin-6-deficient mice. Nature 368: 339-342.

6. Libert C, Takahashi N, Cauwels A, Brouckaert P, Bluethmann H, Fiers W (1994) Response of interleukin-6-deficient mice to tumor necrosis factor-induced metabolic changes and lethality. Eur J Immunol 24: 2237-2242.

7. Linker-Israeli M, Deans RJ, Wallance DJ, Prehn J, Ozeri-Chen T, Klineberg JR (1991) Elevated levels of endogenous IL-6 in SLE. J Immunol 147: 117-123.

8. Grossman RM, Krueger JR, Yourish D, GranelliPiperino A, Murphy D, May LT, Skupper T, Seghal $P$, Gottlieb AB (1989) IL-6 is expressed in high levels in psoriatic skin and stimulates proliferation of cultured human keratinocytes. Proc Natl Acad Sci USA 86: 6367-6372.

9. Guerne PA, Zuraw BL, Vaughan JG, Carson DA, Lotz M (1989) Synovium as a source of IL-6 in vitro: Contribution to local and systemic manifestations of arthritis. J Clin Invest 83: 585-593.
10. Breen EC, Rexai AR, Nakajima K, Beall GN, Mitsuyasu RT, Hirano T, Kishimoto T, MartinezMaza O (1990) Infection with HIV is associated with elevated IL-6 levels and production. J Immunol 144: 480-484.

11. Starnes JHF, Pearce KM, Tewari A, Yim JH, Zou J, Abrams JS (1990) Anti-IL-6 monoclonal antibodies protect against lethal Escherichia coli infection and lethal tumor necrosis factor- $\alpha$ challenge in mice. $J$ Immunol 145: 4185-4191.

12. Nakajima $K$, Martinez-Maza $O$, Hirano $T$, Breen EC, Nishanian PG, Salazar-Gonzalez JF, Fahey JK, Kishimoto T (1989) Induction of IL-6 (B cell stimulating factor- $2 /$ IFN- $\beta 2$ ) production by HIV. $J$ Immunol 142: 531-536.

13. Horii $Y$, Muraguchi A, Suematsu S, Matsuda T, Yoshizaki K, Hirano T, Kishimoto T (1988) Regulation of BSF-2/IL-6 production by human mononuclear cells. Macrophage-dependent synthesis of BSF-2/IL- 6 by T cells. J Immunol 141: 1529-1535.

14. Terebuh PD, Otterness IG, Strieter RM, Lincoln PM, Danforth JM, Kunkel SL, Chensue SW (1992) Biologic and immunohistochemical analysis of IL-6 expression in vivo. Am J Pathol 140: 649-657.

15. Tanaka $M$, Miyazaki $H$, Takeda $Y$, Nakamura $T$, Takeo S (1992) Effect of oral administration of the $\alpha-1,6$-polysaccharide SPR-901 on suppressed Con A-induced IL-2 production in tumour-bearing mice. Int J Immunotherapy 8: 177-184.

16. Watoson JD (1983) Biology and biochemistry of T cell derived lymphokines. I. The coordinate synthesis of interleukin 2 and colony-stimulating factor in a murine T cell lymphoma. J Immunol 131: 293-295.

17. Shirai A, Holmes K, Klinman D (1993) Detection and quantitation of cells secreting IL-6 under physiologic conditions in BALB/c mice. J Immunol 150: 793-799.

18. Czerkinsky C, Nilsson L-A, Nygren H, Ouchtarony O, Tarkowski A (1983) A solid-phase enzymelinked immunospot assay for enumeration of specific antibody-secreting cells. J Immunol Methods 65: 109-121. 
19. Holt PG, Cameron KJ, Stewart GA, Sedgwick JD, Turner KJ (1984) Enumeration of human immunoglobuline-secreting cells by the ELISAplaque method; IgE and IgG isotypes. Clin Immunol Immunopathol 30: 159-164.

20. Van Meide PH, Joosten AM, Hermans P, Kloosterman TC, Olsson T, DeLabie MCDC (1991) Assesment of inhibitory effect of immunosuppressive agents on rat $\mathrm{T}$ cell interferon- $\gamma$ production using an ELISPOT assay. I Immunol Methods 144: 203-213.

21. Fujihashi K, McGhee JR, Beagley KW, McPherson
DT, McPherson SA, Huang C-M, Kiyono H (1993) Cytokine-specific ELISPOT assay, single cell analysis of IL-2, IL-4 and IL-6 producing cells. J Immunol Methods 160: 181-189.

22. Shirai A, Sierra V, Kelly CI, Klinman DM (1994) Individual cells simultaneously produce both IL-4 and IL-6 in vivo. Cytokine 6: 329-336.

23. Tanguay S, Killion JJ (1994) Direct comparison of ELISPOT and ELISA-based assays for detection of individual cytokine-secreting cells. Lymphokine and Cytokine Res 13: 259-263. 